\title{
Regulation of Interleukin-6 and Leptin in Schizophrenia Patients: A Preliminary Analysis
}

\author{
Sasi Neelamekam 1 , Milawaty Nurjono', Jimmy Lee ${ }^{1,2,3}$ \\ ${ }^{1}$ Research Division, Institute of Mental Health, ${ }^{2}$ Department of General Psychiatry 1, Institute of Mental Health, ${ }^{3}$ Office of Clinical Sciences, \\ Duke-NUS Graduate Medical School, Singapore
}

\begin{abstract}
Objective: Immune-inflammatory mediators play a pivotal role in brain signaling and have been increasingly associated with the pathophysiology of schizophrenia. Many studies have indicated an increased level of immune-inflammatory interleukin-6 (IL-6) in schizophrenia. $\mathrm{IL}-6$ is a well-known chief stimulator of inflammation. Of late leptin has also been implicated in the inflammatory pathway of schizophrenia. In this study we measured and compared serum levels of IL-6 and leptin in patients with schizophrenia to healthy controls, and investigated the relationship between $I L-6$ and leptin.

Methods: Serum IL-6 and leptin were determined in 20 patients diagnosed with schizophrenia and in 19 healthy controls matched by gender, age and body mass index (BMI) using commercial Bioplex assays.

Results: Using Mann-Whitney U-test, significantly increased IL-6 levels were found in the patients but there was no significant difference in leptin levels though a trend towards higher leptin was observed in the patients. Spearman correlations did not show any correlation between $\mathrm{IL}-6$ and clinical variables except antipsychotic dosage. Leptin significantly correlated with gender and BMI. A large effect size correlation was observed between IL-6 and leptin in the patients but not in the controls. Multiple regression analysis performed on patients, after adjusting for gender and BMl, revealed there was no significant association between $\|-6$ and leptin.

Conclusion: $I L-6$ and leptin levels may reflect the chronic inflammatory state associated with schizophrenia but further evaluation is required. Also, it is important to consider the confounding effects of obesity in any examination of relationships between groups with regard to cytokines and adipokines.
\end{abstract}

KEY WORDS: Inflammation; Immune; Psychotic disorders; Adipokines.

\section{INTRODUCTION}

The pathogenesis of schizophrenia is widely believed to be based on gene-environment interactions. Genetic studies have suggested that genes related to immune-inflammatory response contribute to the pathophysiology of the disease. ${ }^{1,2)}$ Furthermore, epidemiological and animal studies have indicated that adverse environmental factors such as an unhealthy family environment, a stressful life event, pre-natal and peri-natal exposure to adverse factors increase the risk of developing schizophrenia. ${ }^{3)}$ Altered immune-inflammatory cytokine dysregulation has been postulated as a possible common pathway to both genetic

Received: May 7, 2014 / Revised: July 4, 2014

Accepted: August 11, 2014

Address for correspondence: Jimmy Lee, MBBS, MMed (Psychiatry), $\mathrm{MCl}$

Research Division, Institute of Mental Health, 10 Buangkok View, 539747, Singapore

Tel: +65-63892000, Fax: +65-63891050

E-mail: jimmy_lee@imh.com.sg and environmental components of schizophrenia that occur either in early life or during the acute state in adult life. ${ }^{1,4)}$

Inflammation is an adaptive body response which can be divided into acute inflammation, the initial localized body response to infection or injury which is essential for tissue repair and recovery ${ }^{5)}$ and chronic inflammation, a persistent phenomenon which replaces acute inflammation when the agent causing the inflammation cannot be eliminated. Chronic inflammation can last for several months and even years; it can be detrimental as it could lead to damage of non-infected, healthy and unwounded tissue. ${ }^{6,7)}$ While a number of immune-inflammatory cytokines have been identified, interleukin-6 (IL-6), a proinflammatory interleukin is the chief stimulator of the acute phase response in inflammation which leads to behavior, physiologic, biochemical and nutritional changes during an inflammatory state. ${ }^{8)}$ IL-6 exerts stimulatory effects on $\mathrm{T}$ and $\mathrm{B}$ cells facilitating the transition from acute to chronic state inflammation by altering the immune sys-

(c) This is an Open-Access article distributed under the terms of the Creative Commons Attribution Non-Commercial License (http://creativecommons.org/licenses/by-nc/3.0) which permits unrestricted non-commercial use, distribution, and reproduction in any medium, provided the original work is properly cited. 
tem-changing the nature of leucocyte infiltration from neutrophils to monocyte/macrophages. ${ }^{5)}$ Studies have indicated an increased level of IL-6 in schizophrenia, and a genetic polymorphism in the IL-6 gene. ${ }^{9)}$

Apart from IL-6, leptin, primarily an adipokine, initially discovered to function as a satiety factor has been indicated to function as a proinflammatory cytokine ${ }^{10)}$; and studies have reported altered leptin levels in schizophrenia patients. ${ }^{11)}$ Leptin levels are rapidly increased in response to many acute phase cytokines including IL-6. Leptin is structurally related to the cytokine family and its signal-transducing pathway is also regulated as a cytokine in response to infection and inflammation. ${ }^{12-15)}$ The proinflammatory nature of leptin is supposedly beneficial during acute infections in both rodents and human, but chronically the proinflammatory shift has been suggested to be deleterious. ${ }^{16)}$ More recently, leptin has been recognized to be involved in brain functions such as neuronal development and survival; and various aspects of behavior and cognition which are disturbed in schizophrenia. ${ }^{17)}$ There exists evidence for an association between leptin, cognition and behavior in both rodent and human studies. Leptin has also been reported to modulate activity of mesolimbic dopaminergic neurons in the hypothalamus, which is implicated in schizophrenia. ${ }^{18)}$

IL- 6 and leptin are both secreted by adipose tissue and hence their relationship with obesity has been previously reported. As much as one-third of circulating IL- 6 has been attributed to adipose tissue secretion, with macrophages being the major contributor. ${ }^{19,20)}$ Additionally, leptin is secreted by adipocytes to down-regulate appetite. ${ }^{21)}$ Increasingly, studies indicate that obesity and being overweight are associated with immune-competence alterations. ${ }^{22)}$ Increased bioavailability of active inflammatory molecules, such as IL-6 and leptin, with local and systemic effects, may bring about a vicious cycle, contributing to the overall chronic inflammatory state in obese individuals. Impaired immune function in excess adiposity has been related to insulin resistance, ${ }^{23,24)}$ poor response to and higher incidence of infection, ${ }^{25)}$ all of which negatively impacts health.

While there are suggestions that IL- 6 and leptin are closely associated in obesity, there is a paucity of studies that examine the relationship between IL-6 and leptin in psychiatric illnesses including schizophrenia. Limited studies have provided inconsistent findings examining the link between IL-6 and leptin. Trujillo et al. ${ }^{26)}$ showed that IL-6 increased leptin production; while others concluded that IL-6 inhibited or had no effect on leptin production in human adipocyte cultures. ${ }^{27,28)}$ Therefore, in this study, our objective was to evaluate and compare serum levels of IL-6 and leptin in patients with schizophrenia to healthy controls, and to investigate the relationship between IL-6 and leptin.

\section{METHODS}

\section{Subjects}

Patients diagnosed with schizophrenia above 21 years old were recruited from the Institute of Mental Health in Singapore and matched with healthy controls by gender, age and body mass index. Patients with a history of neurological disorder or head injury; and controls with a history of psychiatric illness were excluded from the study. Participants who reported known immune disorders were excluded from this study. Only participants who were capable of providing written informed consent were recruited. Ethics approval was provided by the National Healthcare Group Domain Specific Review Board.

Demographic and medical information were collected from all participants. Diagnosis of schizophrenia was ascertained on the Structured Clinical Interview for the Diagnostic and Statistical Manual of Mental Disorders 4th edition, text revision (DSM-IV-TR) Axis I Disorders. Weight and height was obtained from all participants and their body mass index (BMI) computed. Clinical symptoms were assessed on the Positive and Negative Syndrome Scale (PANSS) ${ }^{29)}$ Current antipsychotic doses were converted into chlorpromazine equivalents. ${ }^{30,31)}$

\section{IL-6 and Leptin Measurements}

Venous blood was collected from all study participants into serum separating tubes (SST). Immediately after collection, blood samples were allowed to coagulate at room temperature for approximately 30 minutes. Subsequently, serum samples were collected through 10 minutes centrifugation at $4^{\circ} \mathrm{C}$ using a clinical centrifuge (Hettich, Tuttlingen, Germany). Serum IL-6 and leptin were measured using commercially available Bioplex IL-6 and leptin assays (Bio-Rad, Hercules, CA, USA). Briefly, serum samples were diluted $1: 4$ in sample diluents provided and ran in duplicates according to the instruction's manuals. The sensitivity of the kits was $2.6 \mathrm{pg} / \mathrm{ml}$ and $3.1 \mathrm{pg} / \mathrm{ml}$ for IL-6 and leptin respectively.

\section{Statistical Analysis}

Data was analyzed on PASW Statistics software ver. 18.0 (IBM Co., Armonk, NY, USA). Descriptive statistics were tabulated for the patient and control groups. 
Statistical significance was set at $p<0.05$ and was examined using chi-squared test for categorical variables and non-parametric test for continuous variables. Serum IL-6 and leptin between patients and healthy controls were compared using Mann-Whitney $U$-test. Spearman correlation coefficients were calculated to examine the relationships between IL-6, leptin and clinical variables. Multiple regression analysis was used to examine the relationship between IL- 6 and leptin after adjusting for potential confounders.

\section{RESULTS}

Our study comprised of 20 patients and 19 controls. Table 1 shows the demographic and clinical characteristics of the study participants. The patient and control groups were matched by age, sex and BMI. Serum IL-6 and leptin levels in patient and control groups are shown in Fig. 1. Serum IL-6 levels of the patients $(2.4 \mathrm{pg} / \mathrm{ml} \pm 0.6$ $\mathrm{pg} / \mathrm{ml})$ were significantly higher compared to controls $(0.9$ $\mathrm{pg} / \mathrm{ml} \pm 0.2 \mathrm{pg} / \mathrm{ml})(p=0.003)$. Serum leptin levels were higher in the patients $\left(6.1 \times 10^{3} \mathrm{pg} / \mathrm{ml} \pm 1.6 \times 10^{3} \mathrm{pg} / \mathrm{ml}\right)$ compared to the controls $\left(5.2 \times 10^{3} \mathrm{pg} / \mathrm{ml} \pm 1 \times 10^{3} \mathrm{pg} / \mathrm{ml}\right)$, but did not reach statistical significance $(p=0.930)$. In the patient group, serum IL-6 was positively correlated with leptin $(\mathrm{r}=0.52, p=0.02)$ while in the control group there was a weaker and non-significant association $(\mathrm{r}=0.39, p=0.127)$ shown in Figs. 2 and 3. IL-6 correlated significantly with antipsychotic dose $(\mathrm{r}=0.502, p=0.024)$, but there was no significant correlation with gender, age, age of illness onset, BMI, smoking status, duration on illness and psychiatric treatment and type of antipsychotic. Leptin correlated positively with gender $(\mathrm{r}=0.511, p=0.021)$ and $\mathrm{BMI}$ $(\mathrm{r}=0.475, p=0.034)$. In the multiple regression analysis performed on patients, after adjusting for gender and BMI, there was no significant association between IL-6 and leptin (Beta $=0.012, p=0.949$ ).

\section{DISCUSSION}

In the present study IL-6 and leptin were found to be comparatively higher in the patient group, though leptin did not reach statistical significance. Within the patient group IL-6 correlated positively with antipsychotic dose, but not the other clinical variables; while leptin correlated positively with gender and BMI. Conflicting findings between these two proinflammatory cytokines and clinical variables have been reported in schizophrenia. Circulating levels of IL-6 have been reported to show a positive correlation with age, $^{32-34)}$ duration of illness ${ }^{33,35)}$ and age of onset ${ }^{36)}$; while some reported nil or a contrasting relationship. ${ }^{36-39)}$ Reported gender differences have also been inconsistent. ${ }^{33,34,36,40)}$ The inconsistencies in study findings could be a result of differences in sample size, manner in which biological samples were collected and analyzed, assay methods, and potential confounders such as age, gender, BMI and smoking status. Nonetheless, leptin's positive associations with gender and BMI have been consistent with previous reports. ${ }^{11)}$

Table 1. Demographic and clinical information of study participants

\begin{tabular}{|c|c|c|c|c|}
\hline & Total $(n=39)$ & Control $(n=19)$ & Patient $(n=20)$ & $p$-value \\
\hline \multicolumn{5}{|l|}{ Demographics } \\
\hline Gender (male/female) & $25(64.1) / 14(35.9)$ & $11(57.9) / 8(42.1)$ & $14(70) / 6(30)$ & $0.431^{*}$ \\
\hline Age $(y r)$ & $36.7 \pm 6.9$ & $38 \pm 6$ & $35.6 \pm 7.6$ & $0.293^{\dagger}$ \\
\hline Body mass index $\left(\mathrm{kg} / \mathrm{m}^{2}\right)$ & $24.8 \pm 4.1$ & $24.4 \pm 3.5$ & $25.1 \pm 4.7$ & $0.606^{\dagger}$ \\
\hline \multicolumn{5}{|l|}{ Clinical variables } \\
\hline Age of onset (yr) & & & $24.9 \pm 6$ & \\
\hline Duration of illness (yr) & & & $10.4 \pm 7.2$ & \\
\hline PANSS total & & & $38.4 \pm 7.5$ & \\
\hline PANSS positive subscale & & & $10.2 \pm 4.1$ & \\
\hline PANSS negative subscale & & & $9 \pm 3.3$ & \\
\hline \multicolumn{5}{|l|}{ Type of antipsychotic } \\
\hline Typical & & & $9(45)$ & \\
\hline Atypical & & & $8(40)$ & \\
\hline Typical and atypical combined & & & $3(15)$ & \\
\hline \multicolumn{5}{|l|}{ Additional therapy } \\
\hline Anticholinergic & & & $10(50)$ & \\
\hline Selective serotonin re-uptake inhibitor & & & $5(25)$ & \\
\hline Benzodiazepines & & & $2(10)$ & \\
\hline Antipsychotic daily dose in chlorpromazine & quivalents (mg) & & $318 \pm 375$ & \\
\hline
\end{tabular}

Values are presented as number (\%) or mean \pm standard deviation. ${ }^{*}$ Chi-squared test, ${ }^{\dagger}$ Mann-Whitney U-test. 


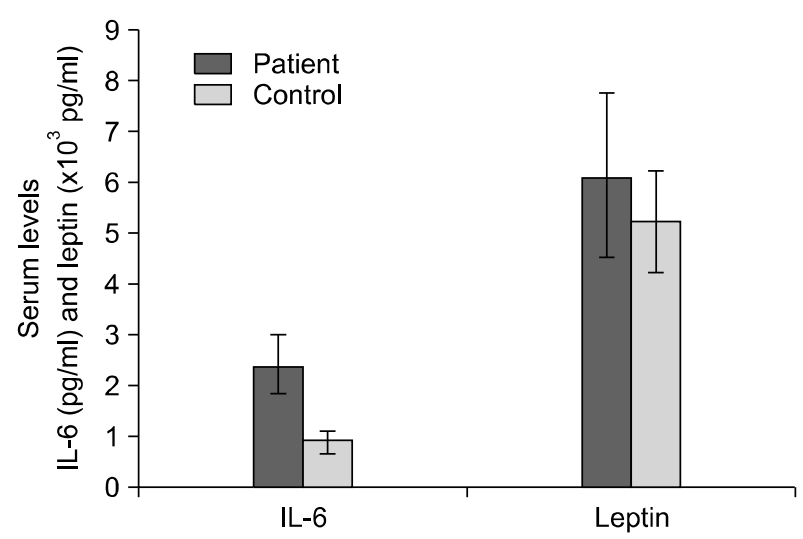

Fig. 1. Data is presented as mean \pm standard error. Interleukin-6 $(\mathrm{IL}-6)$ levels were significantly higher in the patient group $(p=0.003)$ while no significant difference was found in leptin levels between patient and control groups $(p=0.930)$.

A large effect size correlation between IL-6 and leptin in schizophrenia patients was seen in this study. After adjusting for BMI, a surrogate measure for adiposity, there was no longer any association between IL-6 and leptin. This suggests that the relationship between IL- 6 and leptin is moderated by obesity. Obesity has consistently been linked to increased inflammation. ${ }^{41)}$ Adipose tissue has been found to be an active participant modulating immune-inflammatory responses in physiological and pathological processes. ${ }^{42}$ Increased adipose tissue activity could contribute to the inflammatory component of schizophrenia. Moreover, physical inactivity, unhealthy dietary choices, smoking and stress, which are commonly seen in schizophrenia patients, have all been associated with low grade inflammation independent of adipose tissue activity. ${ }^{43-45)}$ In response to infection or inflammatory signals, adipose tissue has been shown to regulate production of acute phase proteins including IL-6, and potential inflammatory modulators such as leptin. ${ }^{46)}$ Therefore, any examination of relationships between groups with regard to cytokines and adipokines would need to take into consideration the confounding effects of obesity.

The present study found IL- 6 to be positively correlated to antipsychotic dose. Though the effect of antipsychotic medications on cytokines have been previously reported, the findings have been inconsistent; with some reports of a positive association, $^{47,48)}$ a negative association ${ }^{37,49-51)}$ and also, absence of any such relationship. ${ }^{35,39,52,53)}$ Antipsychotics, specifically atypical antipsychotics have been known to increase rates of obesity, which leads to upregulation of IL-6 and leptin. ${ }^{54)}$ Though leptin has been purported to have neuroprotective properties; however, in the case of antipsychotic-induced leptin resistance and in obesity, this neuroprotective role

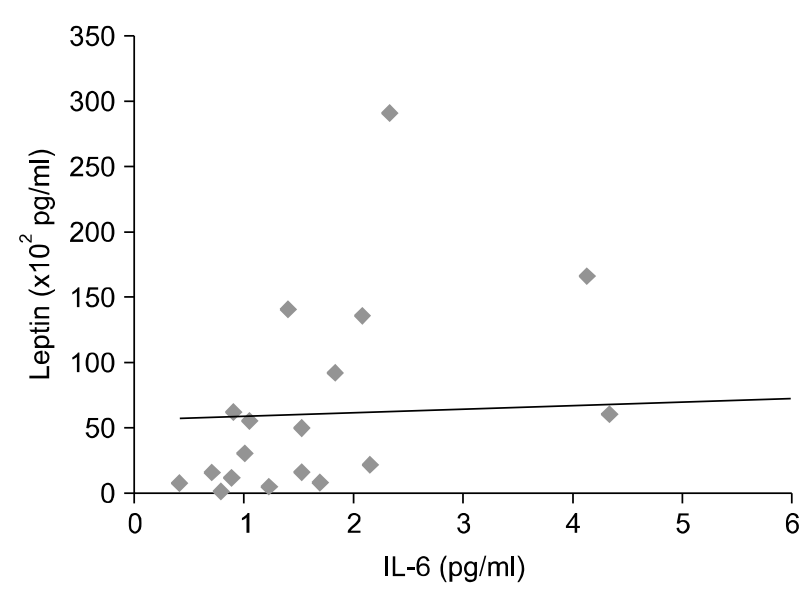

Fig. 2. Scatterplot of serum leptin and interleukin-6 (IL-6) in patients. Significant positive association was observed between $\mathrm{IL}-6$ and leptin in the patient group $(r=0.52, p=0.02)$.

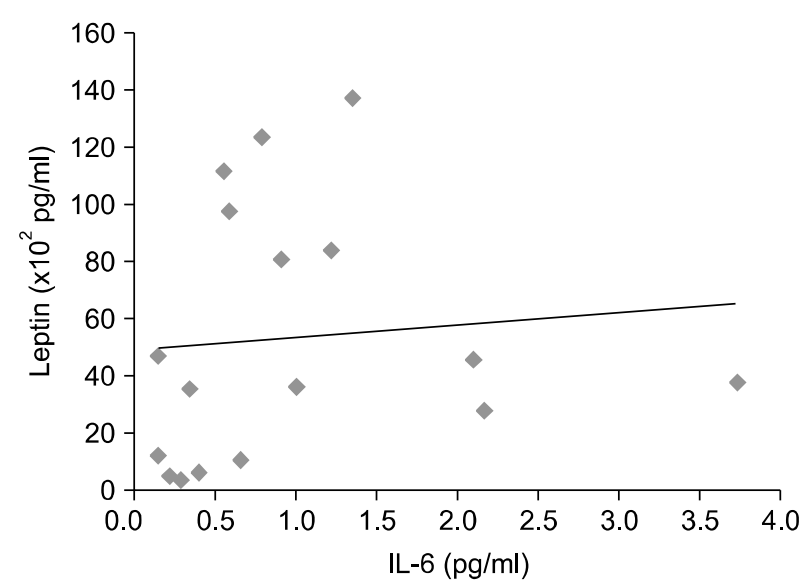

Fig. 3. Scatterplot of serum leptin and interleukin-6 (IL-6) in controls. A weaker and non-significant association was observed between IL-6 and leptin in the control group $(r=0.39, p=0.127)$.

appears unclear. ${ }^{55,56)}$ Therefore, it was suggested that changes in cytokine levels associated with antipsychotic treatment may be secondary to weight gain. ${ }^{57)}$

In the control group, no correlation was found between IL-6 and leptin. Studies have reported lower IL-6 and leptin levels in healthy controls compared to patients with schizophrenia. ${ }^{58,59)}$ Therefore, in the absence of an inflammatory condition or stimuli, and at basal levels, it is unsurprising that IL-6 and leptin levels would be low, and poorly correlated.

The advantages of the study were that it was conducted at a single site which eliminates any potential inter-site variation with regard to venous blood collection and laboratory processes. All participants were carefully assessed for presence of schizophrenia in cases and absence of psychiatric disorders in controls. 
The results reported in the present study need to be interpreted in the context of certain limitations. The small sample size in this study is one limitation to consider that might have led to the negative associations between IL-6, leptin and clinical variables. Other considerations include the chronicity of the illness and treatment, which might have affected expressions of IL-6 and leptin. In addition, the cross sectional nature of the study did not permit us to study temporal relationships between IL-6, leptin and development of obesity in schizophrenia.

In conclusion, elevated serum levels of proinflammatory cytokines such as IL-6 and leptin may reflect a chronic inflammatory state in schizophrenia and leptin could play an important part contributing to the immune-inflammatory milieu. Further studies are warranted to provide insights into the roles of proinflammatory cytokines in the pathophysiology of schizophrenia, as well as in the development of metabolic disorders in schizophrenia.

\section{Acknowledgments}

This study was funded by the National Medical Research Council, Singapore (NMRC/NIG/1017/2010). Dr. Jimmy Lee is supported by the Singapore Ministry of Health's National Medical Research Council under its Transition Award (Grant No.: NMRC/TA/002/2012). Both funding sources had no further role in study design; in the collection, analysis and interpretation of data; in the writing of the report; and in the decision to submit the paper for publication.

Dr. Jimmy Lee has served as a consultant and received an honorarium from Roche.

\section{REFERENCES}

1. Watanabe Y, Someya T, Nawa H. Cytokine hypothesis of schizophrenia pathogenesis: evidence from human studies and animal models. Psychiatry Clin Neurosci 2010;64:217-230.

2. Irish Schizophrenia Genomics Consortium and the Wellcome Trust Case Control Consortium 2. Genome-wide association study implicates HLA-C*01:02 as a risk factor at the major histocompatibility complex locus in schizophrenia. Biol Psychiatry 2012;72:620-628.

3. Walker E, Kestler L, Bollini A, Hochman KM. Schizophrenia: etiology and course. Annu Rev Psychol 2004;55:401-430.

4. Tsuang MT, Stone WS, Faraone SV. Genes, environment and schizophrenia. Br J Psychiatry Suppl 2001;40:s18-s24.

5. Gabay C. Interleukin-6 and chronic inflammation. Arthritis Res Ther 2006;8 Suppl 2:S3.

6. Doorduin J, de Vries EF, Willemsen AT, de Groot JC, Dierckx RA, Klein HC. Neuroinflammation in schizophrenia-related psychosis: a PET study. J Nucl Med 2009;50:1801-1807.

7. Monji A, Kato T, Kanba S. Cytokines and schizophrenia: Microglia hypothesis of schizophrenia. Psychiatry Clin Neurosci 2009;63:257-265.

8. Gabay C, Kushner I. Acute-phase proteins and other systemic responses to inflammation. $N$ Engl J Med 1999;340:448-454.

9. Zakharyan R, Boyajyan A. Inflammatory cytokine network in schizophrenia. World J Biol Psychiatry 2014;15:174-187.

10. Lord GM. Leptin as a proinflammatory cytokine. Contrib Nephro 2006;151:151-164.

11. Sentissi O, Epelbaum J, Olié JP, Poirier MF. Leptin and ghrelin levels in patients with schizophrenia during different antipsychotics treatment: a review. Schizophr Bull 2008;34: 1189-1199.

12. Fantuzzi G, Faggioni R. Leptin in the regulation of immunity, inflammation, and hematopoiesis. J Leukoc Biol 2000;68: 437-446.

13. Faggioni R, Feingold KR, Grunfeld C. Leptin regulation of the immune response and the immunodeficiency of malnutrition. FASEB J 2001;15:2565-2571.

14. Matarese G, Moschos S, Mantzoros CS. Leptin in immunology. J Immunol 2005; 174:3137-3142.

15. Li J, Li F, Zhao A. Inflammation and leptin. Drug Discov Today: Dis Mech 2006;3:387-393.

16. Wisse BE. The inflammatory syndrome: the role of adipose tissue cytokines in metabolic disorders linked to obesity. $J$ Am Soc Nephrol 2004;15:2792-2800.

17. Pollmächer T. An emerging role of leptin in clinical psychiatry. In: Kordon C, Robinson I, Hanoune J, Dantzer R, Christen Y, editors. Brain somatic cross-talk and the central control of metabolism. Research and perspectives in endocrine interactions. Berlin, Heidelberg:Springer;2003. p.143-153.

18. DiLeone RJ. The influence of leptin on the dopamine system and implications for ingestive behavior. Int $J$ Obes (Lond) 2009;33(Suppl 2):S25-S29.

19. Moulin CM, Marguti I, Peron JP, Rizzo LV, Halpern A. Impact of adiposity on immunological parameters. Arq Bras Endocrinol Metabol 2009;53:183-189.

20. Makki K, Froguel P, Wolowczuk I. Adipose tissue in obesityrelated inflammation and insulin resistance: cells, cytokines, and chemokines. ISRN Inflamm 2013;2013:139239.

21. Klok MD, Jakobsdottir S, Drent ML. The role of leptin and ghrelin in the regulation of food intake and body weight in humans: a review. Obes Rev 2007;8:21-34.

22. Martí A, Marcos A, Martínez JA. Obesity and immune function relationships. Obes Rev 2001;2:131-140.

23. Calle EE, Kaaks R. Overweight, obesity and cancer: epidemiological evidence and proposed mechanisms. Nat Rev Cancer 2004;4:579-591.

24. Esser N, Legrand-Poels S, Piette J, Scheen AJ, Paquot N. Inflammation as a link between obesity, metabolic syndrome and type 2 diabetes. Diabetes Res Clin Pract 2014;105:141-150.

25. Falagas ME, Kompoti M. Obesity and infection. Lancet Infect Dis 2006;6:438-446.

26. Trujillo ME, Sullivan S, Harten I, Schneider SH, Greenberg $\mathrm{AS}$, Fried SK. Interleukin-6 regulates human adipose tissue lipid metabolism and leptin production in vitro. J Clin Endocrinol Metab 2004;89:5577-5582.

27. Bruun JM, Pedersen SB, Kristensen K, Richelsen B. Effects of pro-inflammatory cytokines and chemokines on leptin production in human adipose tissue in vitro. Mol Cell Endocrinol 2002;190:91-99.

28. Granowitz EV. Transforming growth factor-beta enhances and pro-inflammatory cytokines inhibit ob gene expression in 3T3-L1 adipocytes. Biochem Biophys Res Commun 1997;240:382-385.

29. Kay SR, Fiszbein A, Opler LA. The positive and negative syndrome scale (PANSS) for schizophrenia. Schizophr Bull 1987;13:261-276.

30. Davis JM. Dose equivalence of the antipsychotic drugs. $J$ Psychiatr Res 1974;11:65-69.

31. Woods SW. Chlorpromazine equivalent doses for the newer 
atypical antipsychotics. J Clin Psychiatry 2003;64:663-667.

32. Wei J, Xu H, Davies JL, Hemmings GP. Increase of plasma IL-6 concentration with age in healthy subjects. Life Sci 1992; 51:1953-1956.

33. Ganguli R, Yang Z, Shurin G, Chengappa KN, Brar JS, Gubbi AV, et al. Serum interleukin-6 concentration in schizophrenia: elevation associated with duration of illness. Psychiatry Res 1994;51:1-10.

34. Haack M, Hinze-Selch D, Fenzel T, Kraus T, Kühn M, Schuld A, et al. Plasma levels of cytokines and soluble cytokine receptors in psychiatric patients upon hospital admission: effects of confounding factors and diagnosis. $J$ Psychiatr Res 1999;33:407-418.

35. Akiyama K. Serum levels of soluble IL-2 receptor alpha, $I L-6$ and $I L-1$ receptor antagonist in schizophrenia before and during neuroleptic administration. Schizophr Res 1999;37:97-106.

36. Dunjic-Kostic B, Jasovic-Gasic M, Ivkovic M, Radonjic NV, Pantovic M, Damjanovic A, et al. Serum levels of interleukin-6 and tumor necrosis factor-alpha in exacerbation and remission phase of schizophrenia. Psychiatr Danub 2013;25:55-61.

37. Frommberger UH, Bauer J, Haselbauer $P$, Fräulin A, Riemann D, Berger M. Interleukin-6-(IL-6) plasma levels in depression and schizophrenia: comparison between the acute state and after remission. Eur Arch Psychiatry Clin Neurosci 1997;247:228-233.

38. Kunz M, Ceresér KM, Goi PD, Fries GR, Teixeira AL, Fernandes BS, et al. Serum levels of $I L-6, I L-10$ and TNF- a in patients with bipolar disorder and schizophrenia: differences in pro- and anti-inflammatory balance. Rev Bras Psiquiatr 2011;33:268-274.

39. Maes M, Meltzer HY, Bosmans E. Immune-inflammatory markers in schizophrenia: comparison to normal controls and effects of clozapine. Acta Psychiatr Scand 1994;89:346-351.

40. Schmitt A, Bertsch T, Tost H, Bergmann A, Henning U, Klimke A, et al. Increased serum interleukin-1beta and interleukin-6 in elderly, chronic schizophrenic patients on stable antipsychotic medication. Neuropsychiatr Dis Treat 2005;1:171-177.

41. Greenberg AS, Obin MS. Obesity and the role of adipose tissue in inflammation and metabolism. Am J Clin Nutr 2006;83:461S-465S.

42. Fantuzzi G. Adipose tissue, adipokines, and inflammation. $J$ Allergy Clin Immunol 2005;115:911-919; quiz 920.

43. Aronson D, Avizohar O, Levy Y, Bartha P, Jacob G, Markiewicz W. Factor analysis of risk variables associated with low-grade inflammation. Atherosclerosis 2008;200: 206-212.

44. Gispen-de Wied CC. Stress in schizophrenia: an integrative view. Eur J Pharmacol 2000;405:375-384.

45. Kiecolt-Glaser JK. Stress, food, and inflammation: psychoneuroimmunology and nutrition at the cutting edge. Psy- chosom Med 2010;72:365-369.

46. Berg AH, Scherer PE. Adipose tissue, inflammation, and cardiovascular disease. Circ Res 2005;96:939-949.

47. Kluge M, Schuld A, Schacht A, Himmerich H, Dalal MA, Wehmeier PM, et al. Effects of clozapine and olanzapine on cytokine systems are closely linked to weight gain and drug-induced fever. Psychoneuroendocrinology 2009;34:118-128.

48. Maes M, Bosmans E, Kenis G, De Jong R, Smith RS, Meltzer HY. In vivo immunomodulatory effects of clozapine in schizophrenia. Schizophr Res 1997;26:221-225.

49. Lü LX, Guo SQ, Chen W, Li Q, Cheng J, Guo JH. Effect of clozapine and risperidone on serum cytokine levels in patients with first-episode paranoid schizophrenia. Di Yi Jun Yi Da Хие Хие Bao 2004;24:1251-1254.

50. Pae CU, Yoon CH, Kim TS, Kim JJ, Park SH, Lee CU, et al. Antipsychotic treatment may alter T-helper (TH) 2 arm cytokines. Int Immunopharmacol 2006;6:666-671.

51. Kim YK, Myint AM, Verkerk R, Scharpe S, Steinbusch H, Leonard B. Cytokine changes and tryptophan metabolites in medication-naïve and medication-free schizophrenic patients. Neuropsychobiology 2009;59:123-129.

52. Lin CC, Chang CM, Chang PY, Huang TL. Increased interleukin-6 level in Taiwanese schizophrenic patients. Chang Gung Med J 2011;34:375-381.

53. Maes M, Bocchio Chiavetto L, Bignotti S, Battisa Tura G, Pioli R, Boin F, et al. Effects of atypical antipsychotics on the inflammatory response system in schizophrenic patients resistant to treatment with typical neuroleptics. Eur Neuropsychopharmacol 2000;10:119-124.

54. Jin H, Meyer JM, Mudaliar S, Jeste DV. Impact of atypical antipsychotic therapy on leptin, ghrelin, and adiponectin. Schizophr Res 2008;100:70-85.

55. Dodd S, Maes M, Anderson G, Dean OM, Moylan S, Berk M. Putative neuroprotective agents in neuropsychiatric disorders. Prog Neuropsychopharmacol Biol Psychiatry 2013:42:135-145.

56. Davis C, Mudd J, Hawkins M. Neuroprotective effects of leptin in the context of obesity and metabolic disorders. Neurobiol Dis 2014. doi:10.1016/j.nbd.2014.04.012. [Epub ahead of print]

57. Tourjman V, Koué MÈ, Kouassi E, Potvin S. Immunomodulatory effects of antipsychotics on inflammatory mediators: a review. Adv Biosci Biotechnol 2012;3:551-565.

58. Murashita $M$, Inoue $T$, Kusumi I, Nakagawa $S$, Itoh $K$, Tanaka T, et al. Glucose and lipid metabolism of long-term risperidone monotherapy in patients with schizophrenia. Psychiatry Clin Neurosci 2007;61:54-58.

59. Beumer W, Drexhage RC, De Wit H, Versnel MA, Drexhage $\mathrm{HA}$, Cohen D. Increased level of serum cytokines, chemokines and adipokines in patients with schizophrenia is associated with disease and metabolic syndrome. Psychoneuroendocrinology 2012;37:1901-1911. 